\title{
A PRODUÇÃO DO CUIDADO POR MEIO DE ATIVIDADES DE ARTE E CULTURA: RELATO DE EXPERIÊNCIA
}

\author{
Matheus Almeida Ramalho \\ Acadêmico do Curso de Graduação em Enfermagem \\ Unidade Acadêmica Especial de Ciências da Saúde. Universidade Federal de Jataí. \\ almeidatheus5@gmail.com
}

INTRODUÇÃO: A criação e implementação do Centro de Atenção Psicossocial (CAPS) é um marco relevante no contexto da Reforma Psiquiátrica. Nos CAPS atuam equipes interdisciplinares, que desempenham ações de prevenção, tratamento e reabilitação, integrando um modelo de cuidado estruturado numa rede de atenção à saúde mental, com serviços comunitários e foco na autonomia dos usuários. OBJETIVO: Relatar a experiência de uma visita técnica ao CAPS do município de Jataí-GO. METODOLOGIA: Trata-se de um relato de experiência, elaborado a partir de uma visita técnica realizada no dia 25 de abril de 2018, na disciplina de Saúde Coletiva, ministrada no primeiro período do Curso de Graduação em Enfermagem da Universidade Federal de Jataí (UFJ). DESCRIÇÃO DA EXPERIÊNCIA: Além de conhecermos a estrutura física e organizacional desse serviço de saúde, destaca-se a realização da "tarde da pintura", uma atividade lúdica e cultural, com foco na socialização, descontração e valorização de formas singulares do processo de livre criação dos usuários. CONCLUSÃO: Foi possível vivenciar aspectos da proposta organizacional e terapêutica do CAPS. Percebeu-se a relevância da realização de atividades lúdicas, culturais e artísticas nos espaços de atenção à saúde. É fundamental que os acadêmicos dos diversos cursos de graduação da área da saúde possam conhecer e participar de atividades como essa, desde o início do curso, buscando compreender a rede de atenção e a produção do cuidado em saúde mental.

Palavras-chave: Humanização da Assistência. Terapia pela Arte. Educação em Saúde. 